\title{
La Nueva España en la crisis de 1808
}

\section{The New Spain through the 1808 crisis}

\author{
Óscar CRUZ BARNEY \\ Investigador Nacional Nivel III \\ Instituto de Investigaciones Jurídicas \\ Universidad Nacional Autónoma de México \\ bufetecruzm@infosel.net.mx
}

Recibido: 28 de octubre de 2011

Aceptado: 23 de enero de 2012

\section{RESUMEN}

Durante el período que media entre la entrada de las tropas de Napoleón en la Península Ibérica y 1821 se sucedieron distintas alternativas en el antiguo Virreinato de Nueva España con respecto a su relación política con la antigua metrópoli; en el desenlace tomaron parte destacada una serie de abogados, que son estudiados en el presente trabajo.

PALABRAS CLAVE: Virreinato de Nueva España, Invasión napoleónica de España, Real Audiencia de México, abogados.

\begin{abstract}
During the period between the entry of Napoleon's troops in the Iberian Peninsula and 1821, several alternatives succeded in the old New Spain Viceroyalty with regard to its political relationship with the former metropolis. In the end, a number of lawyers, which are studied in this paper, took a prominent part in it.
\end{abstract}

KEYWORDS: New Spain Viceroyalty, Spain's Napoleonic invasion, Mexico's Audiencia, lawyers.

\section{RÉSUMÉ}

Au cours de la période comprise entre l'entrée des troupes de Napoléon dans la Péninsule ibérique et 1821, des differentes alternatives se sont produites dans l'ancienne vice-royauté de la Nouvelle Espagne à l'égard de sa relation politique avec l'ancienne métropole. Dans le dénouement ont pris partie un certain nombre d'avocats, qui sont étudiés dans ce document.

MOTS CLÉ : Vice-royauté de la Nouvelle-Espagne, invasion napoléonique de l'Espagne, Audiencia Royale de Mexique, avocats.

\section{ZUSAMMENFASSUNG}

Während der Zeit zwischen dem Einmarsch der Truppen Napoleons auf der Halbinsel und dem Jahr 1821 folgten verschiedene Macht-Alternativen im alten Vizekönigreich des Neuen Spanien im Hinblick auf seine politische Beziehung zur alten Metropole aufeinander. Eine im Beitrag untersuchte Anzahl von Advokaten nahm am Ende hieran teil.

SCHLÜSSELWÖRTER: Vizekönigreich des Neuen Spanien (Virreinato de Nueva España), Napoleonische Invasion Spaniens, Real Audiencia de México, Advokaten. 
SUMARIO: 1. Introducción: la invasión napoleónica a España. 2. La reacción novohispana a la situación en España. 3. Los abogados y el movimiento de 1808: D. Francisco Primo de Verdad y Ramos y D. Juan Francisco de Azcarate. 3.1. D. Francisco Primo de Verdad y Ramos. 3.2. D. Juan Francisco de Azcarate. 4. Bibliografía.

\section{Introducción: La invasión napoleónica a España}

En 1807 fue descubierto el plan de Fernando, hijo de Carlos IV, para derrocarlo. Los encausados en el proceso fueron absueltos por falta de pruebas y desterrados de la Corte y el príncipe heredero obtuvo el perdón real. Desde 1806 Napoleón consideró la invasión a España. En 1808 la turba pidió tanto la destitución de Godoy como la abdicación de Carlos IV, quien le entregó la Corona a su hijo Fernando. ${ }^{1}$

Fernando VII subió al trono por aclamación popular, sin el refrendo de las Cortes del reino. Poco después intervino Napoleón, con la subsecuente guerra que habría de tener importantes repercusiones para España y América. Napoleón instaló en el trono español a José Bonaparte (1808-1813), quien expidió la Constitución de Bayona.

"La invasión francesa, el motín de Aranjuez, la abdicación de Carlos IV, seguida de la de su hijo Fernando VII, la exaltación al trono de José Bonaparte y la guerra de independencia de España, fueron todos ellos acontecimientos que impactaron grandemente en la Nueva España”. La invasión de España y la manera en que se llevó a cabo, trajo consigo el levantamiento generalizado del país contra el emperador. Sostiene Roberto Breña que "es un hecho que la guerra de independencia peninsular funcionó como detonante de la revolución política que tendría como resultado final el derrumbe del Antiguo Régimen...". ${ }^{2}$ Si bien, como sostiene Rafael Estrada Michel, la guerra de independencia en España proporcionó el pretexto para considerar que se había roto el vínculo entre España y las Indias al haber sido sustituida la Monarquía tradicional por una advenediza. ${ }^{3}$

España tuvo, ante la falta de dirección, que crear sus propios órganos rectores conformándolos con miembros de las clases ilustradas, quienes inesperadamente se hallaron a sí mismos en el poder, con lo que las reformas políticas por ellos anheladas se llevarían a efecto con la inevitable revolución política.

El levantamiento en contra de Napoleón en un principio se llevó a cabo de manera local. Así, cada provincia le declaró la guerra al invasor y las juntas locales se subor-

\footnotetext{
${ }^{1}$ Roberto Breña, El primer liberalismo español y los procesos de emancipación de América, 1808-1824. Una revisión historiográfica del liberalismo hispánico, México, El Colegio de México, 2006, p. 73.

${ }^{2}$ Ibidem, p. 83.

${ }^{3}$ Rafael Estrada Michel, Monarquía y Nación. Entre Cádiz y Nueva España, México, Porrúa, 2006, p. 153.
} 
dinaron a las provinciales, quienes se encargaron de llevar a cabo la lucha armada. De la junta de Murcia partió la idea de formar un gobierno central, representativo de todas las provincias y reinos, la cual emitiría las órdenes y pragmáticas a nombre de Fernando VII. Se creó una junta central integrada por los representantes de las provincias el 25 de septiembre de 1808 en Aranjuez, y se denominó Junta Suprema Gubernativa del Reino. Como presidente se nombró al conde de Floridablanca. Esta junta fue la depositaria de la soberanía en ausencia del monarca. Entre sus medidas de gobierno, estableció un Supremo Consejo de España e Indias, en el que fueron integrados todos los consejos del reino.

Muerto el conde de Floridablanca, los reformistas propusieron el asunto de llamamiento a Cortes. Calvo de Rozas, vocal de Aragón, le asignó a las Cortes el cometido principal de elaborar una carta fundamental. El 22 de mayo de 1809 se expidió el respectivo decreto de convocatoria. En él se instituyó una comisión para que llevase a cabo los planes y trabajos base para la convocatoria. Gracias al trabajo de esta comisión, la junta declaró por decreto del 4 de noviembre que las Cortes del reino serían convocadas el 1 de enero de 1810 e iniciarían sus sesiones el 1 de marzo siguiente.

En virtud de las condiciones bélicas imperantes, antes de que se pudieran reunir las Cortes, la junta decidió traspasar sus poderes a un Consejo de Regencia al frente del obispo de Orense, con la obligación de reunir Cortes. Sin embargo, ante la oposición del Consejo de España e Indias, los regentes poco hicieron por juntar las Cortes. Fue gracias a las presiones de los diputados de las juntas provinciales que se logró que la Regencia reiterara la convocatoria a Cortes y se mandó a los que habrían de concurrir a ella que se reuniesen en la isla de León, junto con los representantes de América. En esta nueva convocatoria no se llamó a la nobleza y al clero. Ante esta dificultad, se decidió por la convocatoria sin distinción de estamentos.

La integración de las Cortes de Cádiz favoreció al bando liberal, compuesto principalmente por hombres ilustrados de clase media. Con estas Cortes, "nos hallamos en plena y abierta revolución liberal". Ellas llevaron a cabo una serie de reformas de tipo eminentemente liberal. La más trascendental por articular el sistema de gobierno y cubrir la totalidad del área política fue la Constitución de Cádiz.

La discusión de su articulado se inició en agosto de 1811 y terminó en marzo de 1812; el documento se promulgó, una vez aprobado, el 19 del mismo mes. El 20 de septiembre de 1813 se clausuraron las Cortes generales y extraordinarias que fungieron como constituyentes. El $1^{\circ}$ de octubre se reunieron las ordinarias, de acuerdo con lo prescrito por la Constitución.

\section{La reacción novohispana a la situación en España}

Se dice que el criollismo americano reaccionó ante los acontecimientos peninsulares de una manera que definiría lo que habría de venir en el futuro. La atención y 
el poder se desplazaron hacia los cabildos municipales indianos. ${ }^{4}$ Los sucesos en España tuvieron gran repercusión en la Nueva España. Las abdicaciones de los reyes en favor de Napoleón hicieron surgir las cuestiones de qué hacer para llenar el vacío de poder que éstas representaban. Se decidió dejar al virrey encargado provisionalmente del gobierno mientras no salieran de España las tropas francesas y los reyes no regresasen a ocupar el trono. Sin embargo, se presentaron tres posiciones encontradas: la del Real Acuerdo, que proponía que todo quedase igual, sin llenar así la laguna política; la del Cabildo, que sugería conectar la autoridad del virrey y los organismos superiores con la soberanía; y la del alcalde del crimen, Villaurrutia, quien proponía las Cortes o junta, posición que encontró eco fuera de la capital.

Podemos afirmar que desde el enfrentamiento entre el ayuntamiento de la Ciudad de México y la Real Audiencia en 1808, hasta el triunfo del Ejército Trigarante y de Agustín de Iturbide en 1821, estuvieron en la primera línea de los acontecimientos varios abogados del Ilustre y Real Colegio de Abogados de México: ${ }^{5}$ D. Francisco Primo de Verdad y Ramos, D. Juan Francisco de Azcarate, D. Carlos María de Bustamante y D. José Miguel Guridi y Alcocer, por solo mencionar a algunos. ${ }^{6}$

Las noticias relativas al motín de Aranjuez, de las abdicaciones de Bayona y del levantamiento del pueblo español contra Napoleón llegaron a México entre el 8 de junio y el 28 de julio, ${ }^{7}$ siendo recibidas en general con júbilo, si bien la incertidumbre y el desazón estuvieron presentes. E1 8 de junio se recibió la noticia de la proclamación del nuevo monarca y la caída de Godoy y el 23 de junio se enteraron de la partida de la familia Real a Bayona y de la sublevación del 2 de mayo. El 14 de julio se conoció la noticia de las abdicaciones a favor de los Bonaparte. ${ }^{8}$

Los habitantes novohispanos para ese entonces estaban ya muy divididos, pues los europeos sospechaban de las posibles intenciones independentistas del Cabildo. Éste mantuvo la iniciativa de solicitar la reunión de una junta representativa del reino. Dicha junta estaría compuesta por la Real Audiencia, el arzobispo, la ciudad y diputaciones

\footnotetext{
${ }^{4}$ Roberto Breña, op. cit., p. 87.

${ }^{5} \mathrm{La}$ autorización para la fundación del Colegio fue otorgada por Carlos III mediante Real Cédula del 21 de junio de 1760, además le otorgó el título de Ilustre y lo admitió bajo su real protección. Precisamente uno de los timbres que significaban un mayor orgullo para el Colegio era el de contar con tal denominación. Finalmente, mediante reales cédulas de 6 de noviembre y 24 de diciembre de 1766 se incorporó por filiación el Colegio de Abogados de México al de Madrid, con los mismos privilegios y gracias. Los primeros estatutos se imprimieron en Madrid en 1760, en la imprenta de Gabriel Ramírez. Después de diversas reformas, no fue sino hasta 1808 cuando se elaboraron nuevos estatutos, y el 21 de marzo de ese año el virrey José de Iturrigaray autorizó su impresión.

${ }^{6}$ Véase nuestro trabajo "Los abogados y la independencia de México", en Milena Koprivitza, La guerra de conciencias. Monarquía o independencia en el mundo hispánico y lusitano, Tlaxcala, Gobierno del Estado de Tlaxcala, 2010.

${ }^{7}$ Marco Antonio Landavazo, La máscara de Fernando VII. Discurso e imaginario monárquicos en una época de crisis. Nueva España, 1808-1822, México, El Colegio de México, Universidad Michoacana de San Nicolás de Hidalgo, El Colegio de Michoacán, 2001, p. 49.

${ }^{8}$ Idem.
} 
de los tribunales, cuerpos eclesiásticos y seculares, nobleza, ciudadanos principales y militares. Su función sería la de deliberar y decidir sobre asuntos graves y su actuación sería provisional, entretanto se reunían los representantes del reino. El virrey Iturrigaray compartía con el Ayuntamiento el parecer de que la junta era necesaria para conservar los derechos del rey y seguridad del reino. Dicha junta se celebró el 9 de agosto, y en ella se acordó reconocer a Fernando VII, no obedecer las órdenes del emperador ni de sus lugartenientes, considerar al virrey como legal y verdadero lugarteniente de Fernando VII en la Nueva España y considerar subsistentes a la Audiencia y demás tribunales, que seguirían sin variación en el ejercicio de sus funciones.

A mediados del mismo mes, arribaron a la Nueva España dos representantes de la Junta de Sevilla, que pretendía ser suprema de España e Indias; Manuel de Jaúregui y Juan Gabriel Jabat. Dentro de sus pretensiones estaba el reconocimiento de su representada, para lo que Iturrigaray ofreció celebrar una nueva junta para estudiar la petición. El 31 de agosto se llevó a cabo y se decidió reconocer a la de Sevilla como soberana en lo referente a guerra y hacienda; lo mismo se haría en cuanto a gobierno y justicia, una vez que se tuviesen las pruebas suficientes de que las de Castilla lo habían hecho. Unas horas después Iturrigaray recibió noticias de los comisionados de la Junta de Oviedo, en donde le informaban de la anarquía en que se encontraba España y del hecho de que todas las juntas se señalaban a sí mismas como supremas. Por ello, decidió convocar a una nueva junta para el día siguiente, $1^{\circ}$ de septiembre de 1808 , en la que se optó suspender el reconocimiento anteriormente otorgado a la de Sevilla. Ante esto, el virrey solicitó a los asistentes que le entregasen sus pareceres por escrito para examinarlos en una nueva junta a celebrarse el día 9. En la nueva reunión, se decidió definitivamente no reconocer la superioridad de la Junta de Sevilla.

El virrey estaba dispuesto a integrar una verdadera representación del virreinato, por lo que surgió la cuestión del llamamiento de representantes del reino, aunque las discusiones se centraron en la procedencia de convocatoria de una junta o asamblea general.

Don José de Iturrigaray, fue depuesto el 15 de septiembre de 1808 por un grupo de 330 individuos y sustituido por Don Pedro de Garibay calificado de "octogenario mariscal", 9 nombrado por la Real Audiencia que reconoció a la Junta Central de España, con la subsecuente suspensión de todos los proyectos de reforma. Garibay ocupó el cargo del 16 de septiembre de 1808 al 19 de julio de 1809 .

El Virrey José de Iturrigaray había intentado generar la mayor cantidad posible de caudales para la Real Hacienda, lo que incluyó la aplicación de las disposiciones sobre la Consolidación de Vales Reales. No solamente intentó una reforma integral al Consulado de México al ordenarle regir sus procedimientos y establecimiento de Diputaciones Consulares conforme a la Real Cédula de Erección del Consulado de Guadalajara, atentó además contra los intereses de los comerciantes dedicados al

\footnotetext{
${ }^{9}$ Ibidem, p. 89.
} 
abasto de carne para la Ciudad de México introduciendo un nuevo impuesto sobre el mismo y otro más sobre el aguardiente de caña.

Guillermina del Valle Pavón señala que los miembros del Consulado de México (81 de los 330 individuos implicados, casi la mitad de los 169 comerciantes matriculados en el Consulado en 1807) ${ }^{10}$ participantes en el golpe de 1808 que llevó a la destitución del Virrey José de Iturrigaray tuvieron dos objetivos fundamentales: por una parte impedir que progresara la propuesta del cabildo de la Ciudad de México y hacer patente su descontento con las políticas emprendidas por Iturrigaray para obtener mayores recursos fiscales ordinarios y extraordinarios. Dichas políticas perjudicaban los intereses de varios de los comerciantes participantes en el golpe. ${ }^{11}$

La caída de Iturrigaray generó algunas protestas y los apresamientos subsecuentes, así como la propuesta en un caso de coronar a un descendiente de Moctezuma, como solución a la crisis provocada por el golpe. ${ }^{12}$ A partir de entonces, los principales dirigentes del grupo criollo fueron encarcelados o desterrados. Unos meses después, la Junta Central de España sustituyó a Garibay por el arzobispo Francisco de Lizana, quien siguió una política conciliadora, lo que desagradó a los del partido europeo, que finalmente logró la destitución de Lizana en 1810. Hasta la llegada de su sustituto, Francisco Xavier Venegas, la Real Audiencia tomó las riendas del gobierno.

Lo anterior trajo consigo la radicalización de la actitud de los criollos y el surgimiento de las conspiraciones de Valladolid y Querétaro. ${ }^{13}$

En Querétaro, Miguel Hidalgo, Ignacio Allende y Juan Aldama se reunían regularmente, con proyectos similares a los del ayuntamiento en 1808. Hidalgo y Allende habían adoptado un plan concebido en México de integrar una junta compuesta por representantes de los diversos cuerpos bajo la dirección de la clase media por medio de los Cabildos. Al ser descubiertos, Hidalgo decide, en la noche del 15 de septiembre, llamar en su auxilio al pueblo de Dolores, de donde era párroco.

Señala Alejandro Mayagoitia que las novedades que se sucedieron desde la instauración de las Cortes generales y extraordinarias hasta el retorno de D. Fernando VII y la derogación de la Constitución de Cádiz sin duda fueron objeto de ponderación por los abogados miembros del Ilustre y Real Colegio de Abogados de México, afectando en mucho la mentalidad de los letrados. "El fin de los cuerpos tradicionales,

\footnotetext{
${ }^{10}$ Guillermina del Valle Pavón, "Participación de los mercaderes del Consulado de México en el golpe de 1808", en María del Cármen Collado (coord.), Miradas recurrentes II. La Ciudad de México en los siglos XIX y XX, México, Instituto Mora, Universidad Autónoma Metropolitana, 2004, p. 157. Sobre el tema véase también Matilde Souto Mantecón, Mar abierto. La política y el comercio del Consulado de Veracruz en el ocaso del sistema imperial, México, El Colegio de México, Instituto Mora, 2001.

${ }^{11}$ Ibidem, pp. 147-148.

${ }^{12}$ Alfredo Ávila, “Nueva España, 1808-1809”, en Roberto Breña (editor), En el umbral de las revoluciones hispánicas: el bienio 1808-1810, México, El Colegio de México, Centro de Estudios Políticos y Constitucionales, 2010, p. 147.

${ }^{13}$ Marco Antonio Landavazo, op. cit., p. 50.
} 
de su influencia y poder, se aceleró y el surgimiento de un nuevo hombre se vislumbraba como una realidad muy cercana". ${ }^{14}$

En el periodo que corre de 1808 a 1821 el Colegio buscó no solamente defender sus privilegios como corporación sino aumentarlos. En 1809 se solicitó se les concediese el uso de uniforme y de una medalla que contuviese el busto del Rey, símbolos que los distinguiesen como fieles vasallos. Se aseguraba que la abogacía era una milicia togada al trabajar como soldados por los intereses y la conservación de la patria, sosteniendo los derechos del altar y del trono. El uniforme se utilizaría en aquellos casos en que no se utilizase el traje curial, el cual solamente estaba permitido en los estrados y serviría para distinguirles del resto de las clases del Estado. ${ }^{15} \mathrm{~A}$ lo anterior había que añadir que todos los profesores de la abogacía gozaban del privilegio de nobleza personal reconocido por el Rey Carlos III mediante real decreto de 17 de noviembre de 1765. ${ }^{16}$ Finalmente, se buscó justificar el uniforme con el argumento de que eliminaría la necesidad de adquirir varios trajes decentes al año con los cuales presentarse ante el público, lo que significaría un notable ahorro, especialmente si se consideraban las variaciones de la moda. ${ }^{17}$

Inclusive aprovechando el viaje del miembro del Colegio Miguel Guridi y Alcocer a las Cortes de Cádiz como diputado, se solicitó el título de fidelísimo. Cabe señalar que no obtuvo ninguno de los privilegios señalados. En 1811 se quejaba el promotor del Colegio López Matoso de la pérdida de formalidad en las juntas del Colegio por la falta de uso del traje curial. ${ }^{18}$

\section{Los abogados y el movimiento de 1808: D. Francisco Primo de Verdad y Ramos y D. Juan Francisco de Azcarate}

\subsection{Francisco Primo de Verdad y Ramos}

Calificado como protomártir de la independencia, nació en la Hacienda de Ciénega del Rincón, Aguascalientes el 19 de junio de 1760. Hizo sus estudios en el Real Colegio de San Ildefonso de la Ciudad de México. Fue abogado de la Audiencia de México, antiguo Consiliario del Ilustre y Real Colegio de Abogados de México y su

\footnotetext{
${ }^{14}$ Alejandro Mayagoitia, "De real a nacional: el Ilustre Colegio de Abogados de México", en La supervivencia del Derecho Español en Hispanoamérica durante la época independiente. Cuadernos del Instituto de Investigaciones Jurídicas, Instituto de Investigaciones Jurídicas, UNAM, México, 1998, p. 412. ${ }^{15}$ Ibidem, pp. 419-420.

${ }^{16}$ Lo que los exentaba de torturas, pechos y demás posibles cargas. La nobleza personal no implicaba de ninguna manera declaración de nobleza de sangre. Véase Real Decreto de 17 de noviembre de 1765 , en Antonio Xavier Pérez y López, Teatro de la Legislación Universal de España e Indias, Imprenta de Antonio Espinoza, Madrid, 1791, tomo, I, p. 62.

${ }^{17}$ Alejandro Mayagoitia, "De real a nacional..., p. 420.

${ }^{18}$ Ibidem, p. 421.
} 
sinodal. Al Colegio se incorporó el 16 de mayo de $1784 .{ }^{19}$ El cargo de Consiliario lo ejercía ya en $1792^{20}$ y en 1794 tenía su domicilio en la Calle del Coliseo Número $8,{ }^{21}$ un año después en 1795 lo tenía en Puente del Espíritu Santo Número 3. ${ }^{22}$

Primo de Verdad decía de sí mismo haber logrado que su estudio fuera uno de los más proveídos de asuntos y que se hayan puesto a su dirección muchos de los más arduos que se han versado en los tribunales de la corte. ${ }^{23}$

En 1804 Primo de Verdad era ya Regidor Honorario y Abogado del Ayuntamiento de México, Examinador Perpetuo del Colegio de Abogados. Seguía viviendo en Puente del Espíritu Santo Número 3. ${ }^{24}$

Dos años después, en 1806 era nuevamente Consiliario y ya Promotor Fiscal y Examinador Perpetuo del Colegio de Abogados, Regidor Honorario y Síndico del Ayuntamiento de México. Mantenía su residencia en Puente del Espíritu Santo Número 3. ${ }^{25}$

El cargo de Regidor Honorario y Síndico del Ayuntamiento de México lo seguía ocupando Primo de Verdad cuando junto con Juan Francisco de Azcárate promovió el plan que como veremos, planteaba la independencia de México. Primo de Verdad fue apresado el 16 de septiembre de 1808 un día después del golpe contra Yturrigaray y murió inesperadamente el 4 de octubre siguiente. ${ }^{26}$

${ }^{19}$ Lista de los Abogados que se hallan matriculados en el Ilustre y Real Colegio de esta Nueva España, con expresión de su antigüedad en exámen é incorporación en esta Real Audiencia como lo denotan las fechas de cada Casilla y números del margen. Sirve para este presente año de 1792, s/f, s/e, pág. 3. ${ }^{20}$ Idem.

${ }^{21}$ Lista de los Abogados que se hallan matriculados en el Ilustre y Real Colegio de esta Nueva España, Con expresión de su antigüedad en exámen é incorporación en esta Real Audiencia, como lo denotan las fechas de cada casilla y números del margen, habitaciones y empleos que obtienen en el Colegio. Sirve para este presente año de 1794, En México, Por los Herederos de Don Felipe de Zúñiga y Ontiveros, Calle del Espíritu Santo, 1794, p. 15.

${ }^{22}$ Lista de los Abogados que se hallan matriculados en el Ilustre y Real Colegio de esta Nueva España, Con expresión de su antigüedad en exámen é incorporación en esta Real Audiencia, como lo denotan las fechas de cada casilla y números del margen, habitaciones y empleos que obtienen en el Colegio. Sirve para este presente año de 1795, En México, Por Don Mariano Joseph de Zúñiga y Ontiveros, Calle del Espíritu Santo, 1795, p. 14.

${ }^{23}$ Alejandro Mayagoitia, "Aspirantes al Ilustre y Real Colegio de Abogados de México: extractos de sus informaciones de limpieza de sangre (1760-1823)", Ars Iuris, Facultad de Derecho, Universidad Panamericana, Núm. 24, 2000, p. 416.

${ }^{24}$ Lista de los Abogados que se hallan matriculados en el Ilustre y Real Colegio de México, Con expresión del día de su exámen ó incorporación, y la de sus empleos y habitaciones, denotándose la antigüedad con el número marginal, y los ausentes con esta señal S. Sirve para este presente año de 1804, En México, Por Don Mariano Joseph de Zúñiga y Ontiveros, Calle del Espíritu Santo, 1804, p. 21.

${ }^{25}$ Lista de los individuos matriculados en el Ilustre y Real Colegio de Abogados de México, Con expresión del día del exámen de éstos, de su incorporación y de la de los Señores Ministros, y la de sus empleos y habitaciones, denotándose los ausentes con la letra cursiva. Sirve para el presente año de 1806, En México, Por Don Mariano Joseph de Zúñiga y Ontiveros, Calle del Espíritu Santo, 1806, p. 1.

${ }^{26}$ José María Miquel y Vergés, Diccionario de insurgentes, 2a ed., México, Porrúa, 1980, sub voce "Primo de Verdad y Ramos, Francisco". 


\subsection{Juan Francisco de Azcarate y Lezama}

D. Juan Francisco de Azcarate y Lezama nació en la Ciudad de México y fue bautizado en el Sagrario Metropolitano el 16 de julio de 1768. Fue colegial de San Pedro y San Pablo y de San Ildefonso de México en donde hizo sus primeros estudios. Hijo de José Andrés de Azcárate y de Manuela Lezama. ${ }^{27}$

El 4 de octubre de 1790 se matriculó en el Ilustre y Real Colegio de Abogados de México y en 1794 vivía en la Calle de San Joseph el Real Número $2,{ }^{28}$ mudándose a la Calle de Capuchinas Número 1 en 1795. ${ }^{29}$

Para 1797 era Consiliario Noveno ${ }^{30}$ y un año después en 1798 lo fue Séptimo del Colegio $^{31}$ y tenía su domicilio en la Calle de las Capuchinas número $\cdot 8$, domicilio que habría de mantener al menos hasta 1803. En 1804 era ya regidor honorario y síndico personero de la Ciudad de México con domicilio en la Calle de San Agustín número 7. Ese carácter y domicilio lo mantenía en $1806 .^{32}$

En 1812 era secretario de la Junta de Caridad, consiliario y examinador del Colegio de Abogados. ${ }^{33}$

\footnotetext{
${ }^{27}$ Alejandro Mayagoitia, “Aspirantes al Ilustre y Real Colegio de Abogados de México: extractos de sus informaciones de limpieza de sangre (1760-1823)", Ars Iuris, Facultad de Derecho, Universidad Panamericana, Núm. 21, 1999, pp. 341-342.

${ }^{28}$ Lista de los Abogados que se hallan matriculados en el Ilustre y Real Colegio de esta Nueva España, Con expresión de su antigüedad en exámen é incorporación en esta Real Audiencia, como lo denotan las fechas de cada casilla y números del margen, habitaciones y empleos que obtienen en el Colegio. Sirve para este presente año de 1794, En México, Por los Herederos de Don Felipe de Zúñiga y Ontiveros, Calle del Espíritu Santo, 1794, p. 17.

${ }^{29}$ Lista de los Abogados que se hallan matriculados en el Ilustre y Real Colegio de esta Nueva España, Con expresión de su antigüedad en exámen é incorporación en esta Real Audiencia, como lo denotan las fechas de cada casilla y números del margen, habitaciones y empleos que obtienen en el Colegio. Sirve para este presente año de 1795, En México, Por Don Mariano Joseph de Zúñiga y Ontiveros, Calle del Espíritu Santo, 1795, p. 17.

${ }^{30}$ Lista de los Abogados que se hallan matriculados en el Ilustre y Real Colegio de esta Nueva España, Con expresión de su antigüedad en exámen é incorporación en esta Real Audiencia, como lo denotan las fechas de cada casilla y números del margen, habitaciones y empleos que obtienen en el Colegio. Sirve para este presente año de 1797, En México, Por Don Mariano Joseph de Zúñiga y Ontiveros, Calle del Espíritu Santo, 1797, p. 2.

${ }^{31}$ Lista de los Abogados que se hallan matriculados en el Ilustre y Real Colegio de esta Nueva España, Con expresión de su antigüedad en exámen é incorporación en esta Real Audiencia, como lo denotan las fechas de cada casilla y números del margen, habitaciones y empleos que obtienen en el Colegio. Sirve para este presente año de 1798, En México, Por Don Mariano Joseph de Zúñiga y Ontiveros, Calle del Espíritu Santo, 1798, p. 2.

${ }^{32}$ Lista de los individuos matriculados en el Ilustre y Real Colegio de Abogados de México, Con expresión del dñia del exámen de éstos, de su incorporación y de la de los Señores Ministros, y la de sus empleos y habitaciones, denotándose los ausentes con la letra cursiva. Sirve para el presente año de 1806, En México, Por Don Mariano Joseph de Zúñiga y Ontiveros, Calle del Espíritu Santo, 1806, p. 3.

${ }^{33}$ Alejandro Mayagoitia, "Las listas de matriculados impresas por el Ilustre y Real Colegio de Abogados de México”, Ars Iuris, Facultad de Derecho, Universidad Panamericana, Núm. 27, 2002, pp. 383-384.
} 
Siendo regidor honorario del ayuntamiento de México sucedieron los hechos ya señalados en Madrid. Azcárate "que ejercía grande influencia en el ayuntamiento", hizo a nombre de este una representación al Virrey Iturrigaray el día 19 de julio, mediante la cual probaba que las abdicaciones reales eran nulas y que se debía reconocer a Fernando VII. ${ }^{34}$ En tanto el monarca no recuperase su libertad, la soberanía residía en el Reino y en las clases que lo formaban, particularmente en los tribunales superiores y en los cuerpos o corporaciones que llevaban la voz pública, quienes la conservarían para devolverla al legítimo sucesor, debiendo gobernarse el reino por las leyes establecidas.

En consecuencia de lo anterior, la Ciudad de México en representación de todo el reino de la Nueva España sostendría los derechos de la casa reinante y para ello solicitaba al Virrey continuase provisionalmente como tal sin entregar el gobierno ni a la misma España hasta en tanto ésta estuviese ocupada por los franceses, sin admitir a otro virrey, prestando juramento y pleito homenaje al reino ante el real acuerdo y en presencia del ayuntamiento de los tribunales, debiendo gobernar conforme a las leyes establecidas. ${ }^{35}$

"Se trataba de proponer la autonomía para México evitando que se mude dinastía" ${ }^{36}$

El fundamento del juramento propuesto por Azcárate se encuentra en las Siete Partidas,${ }^{37}$ específicamente en la Ley $5^{\mathrm{a}}$, Tít. XV, de la Segunda Partida que establece que el señorío del reino no podía partirse ni enajenarse.

Dicha Ley se titula Como el Rey, e todos los del Reyno deven guardar que el Señorio sea siempre uno, e no lo enajenen, ni lo departan. Prohíbe que el señorío del reino sea dividido o enajenado por tres razones:

Primera: Por hacer lealtad a su Señor, demostrando que aman su honra y su pro.

Segunda: Por honra de si mismos, porque cuanto mayor sea el Señorío y su tierra, tanto más serán ellos preciados y honrados.

Tercera: Por guarda del Rey y de sí mismos, porque mientras mayor sea el señorío, mejor podrán guardar del Rey y de sí mismos.

Por eso, se dispuso que cuanto fallece el Rey, el nuevo monarca debía de jurar si tenía edad de catorce años, que nunca en la vida dividiría o enajenaría el Señorío. Este juramento debían hacerlo en las villas reuniendo al Consejo y también los hombres señalados, hombres y mujeres, grandes y pequeños.

\footnotetext{
34 “Representación que el Ayuntamiento de México presentó al virrey José de Iturrigaray, 19 de julio de 1808", en Virginia Guedea, Textos insurgentes (1808-1821), México, UNAM, 1998, Biblioteca del Estudiante Universitario 126, pp. 3-11. Véase también el Acta de la sesión del Ayuntamiento de México de 19 de julio de 1808, en Luis Navarro García, El golpe fidelista de México en 1808, Cádiz, Universidad de Cádiz, 2009, pp. 74 y ss.

${ }^{35}$ Ibidem, p. 8. Véase asimismo Lucas Alamán, Historia de Méjico, $3^{\text {a }}$ ed., Ed. Jus, Tomo Primero, pp. 112-113.

${ }^{36}$ Rafael Estrada Michel, op. cit., p. 156.

${ }^{37}$ Las Siete Partidas del Sabio Rey Don Alonso el Nono, glosadas por el Licenciado Gregorio López, del Consejo Real de Indias de S.M., Madrid, En la Oficina de Benito Cano, 1789, Tomo I.
} 
Establece la Ley $5^{\mathrm{a}}$ que debe el pueblo guardar que el Señorío sea toda la vida uno y no consentir de ningún modo que se enajene o se divida. Los que lo hicieren errarían primero contra Dios, dividiendo lo que el juntó, despreciando y teniendo por vil lo que él diera por honra. Segundo contra la palabra del Profeta Isaías que dijo: 42:8 ;Yo soy el Señor, este es mi Nombre! ¡No cederé mi gloria a ningún otro ni mi alabanza a los ídolos! y errarían contra sí mismos si aconsejasen al Rey para hacerlo y no lo estorbasen cuanto pudiesen para evitarlo. Los que no lo hicieren cometerían traición y así deben ser castigados.

Se sostiene en el Diccionario Universal de historia y de geografia, de Don Manuel Orozco y Berra que con esta representación de Azcárate se dio inicio en México a la revolución de independencia y el desencadenamiento de la serie de hechos que produjeron primero la prisión, destitución y destierro de Iturrigaray y después la idea de independencia, ya que se pensó que la representación del ayuntamiento redactada por Azcárate a eso iba dirigida. ${ }^{38}$

Para Luis Navarro García es evidente que entre el Cabildo y el Virrey había un contacto previo, para mantener el reino a disposición de Carlos IV y sus sucesores. Lo considera en realidad un pronunciamiento carlista ya que "suponía dar por nula la abdicación de Aranjuez pocas semanas después de que hubiese sido proclamado el nuevo rey Fernando con repiques de campanas y ceremonias religiosas". Constituye además una reclamación por parte de la Ciudad de México de su pretendido derecho a participar junto con otros cuerpos y autoridades en el gobierno virreinal. ${ }^{39}$ En este sentido, la Real Audiencia de México habría de señalar tiempo después de superado el suceso, el 28 de abril de 1809, que el Ayuntamiento de la Ciudad de México suponía que "el legítimo soberano de España y de las Indias no era el Señor Don Fernando 7 sino el Señor Don Carlos $4^{\text {to }}$, cuyos derechos dijo estaba dispuesto a sostener a todo trance...". 40

Cabe destacar en contraste la actitud de la Ciudad de Guadalajara, que omitiendo cualquier referencia a Carlos IV, "se pronunció por Fernando VII y declaró la guerra a Francia, apoyada por la Audiencia, México, aunque propuso que el reino se pusiera en estado de defensa y declaró insubsistentes la abdicación de Carlos IV y la renuncia del príncipe de Asturias, siguió reconociendo al primero... como eventual rey de España y de las Indias, y supletoriamente, a su hijo Fernando...". ${ }^{41}$

A la propuesta del ayuntamiento se respondió por la Real Audiencia de México con un Voto Consultivo el 21 de julio en el que se decía que en el presente estado de

\footnotetext{
38 “Azcárate y Lezama, D. Juan Francisco", en Diccionario Universal de historia y de geografia, Imprenta de F. Escalante, Librería de Andrade, México, 1853, t. I.

${ }^{39}$ Luis Navarro García, op. cit., pp. 28-31

${ }^{40}$ Véase Reflexiones sobre el cuaderno de juntas y otros que tienen relación con él, México, 28 de abril de 1809, en Luis Navarro García, op. cit., p. 131.

${ }^{41}$ José Herrera Peña, Soberanía, representación nacional e independencia en 1808, México, Senado de la República, Gobierno del Distrito Federal, 2009, p. 49.
} 
cosas, nada se ha alterado en orden a las potestades establecidas legítimamente y deben todas continuar como hasta aquí sin necesidad del nombramiento y juramento propuesto por la Ciudad de México al Virrey.

Una segunda representación del Ayuntamiento de México se hace el 5 de agosto urgiendo se convoque a una Junta de Gobierno presidida por el Virrey y compuesta por la Real Audiencia, el Sr. Arzobispo, la Nobilísima Ciudad y las diputaciones de los tribunales, cuerpos eclesiásticos y seculares, la nobleza, los ciudadanos principales y el estado militar. ${ }^{42}$

Iturrigaray decide reunir a una junta pese a no contar con el acuerdo de la Real Audiencia. En la junta se enfrentaron Francisco Primo de Verdad y el inquisidor decano Bernardo de Prado y Obejero sobre el concepto del pueblo y la soberanía. Se acordó reiterar la lealtad a Fernando VII no reconocer a gobierno alguno no establecido por él. El Virrey emitirá una proclama en la que resalta la ratificación de su carácter de tal. ${ }^{43}$

La desgracia del Virrey la noche del 15 de septiembre de 1808, acarreó la de Primo de Verdad y el Lcdo. Azcárate, quienes dirigían al ayuntamiento considerado la cabeza del partido novohispano frente al europeo. El golpe de estado encabezado por Gabriel de Yermo tendría como consecuencias la exacerbación del resentimiento criollo y el surgimiento de las conspiraciones de Valladolid y Querétaro. Los insurgentes de 1810 llegarían a decir que el golpe de estado era una de las causas de la rebelión, por haber ofendido la dignidad del pueblo. ${ }^{44}$

Azcárate fue procesado y encarcelado por tres años, liberado en 1811, "quedando el interesado en buena opinión y fama que se tenía de su honor y circunstancias, antes de los sucesos de 1808", señala la sentencia liberatoria.

Una vez consumada la independencia en 1821 por Don Agustín de Iturbide, Azcárate fue nombrado miembro de la Junta Provisional Gubernativa del Imperio Mexicano, siendo en ese momento síndico segundo del Ayuntamiento de México. ${ }^{45}$ Es uno de los firmantes del Acta de Independencia del Imperio Mexicano.

Fue postulado como vicepresidente de la citada Junta, sin haber resultado electo para el cargo ${ }^{46}$ Integró la Comisión de Relaciones Exteriores junto con el Conde de Heras y el Marqués de Rayas. ${ }^{47}$ Se opuso en su momento a ofrecerle a España una alianza defensiva y ofensiva por considerar que sería ruinosa, quedando la oferta en

\footnotetext{
42 "Representación que el Ayuntamiento de México presentó al virrey José de Iturrigaray, 5 de agosto de 1808", en Virginia Guedea, Textos insurgentes..., pp. 11-16.

${ }^{43}$ Alfredo Ávila, op. cit., p. 140.

${ }^{44}$ Marco Antonio Landavazo, op. cit., p. 51.

${ }^{45}$ Diario de las sesiones de la Soberana Junta Provisional Gubernativa del Imperio Mexicano, instalada según previenen el Plan de Iguala y los Tratados de la Villa de Córdova, México, En la imprenta Imperial de D. Alexandro Valdés, 1821, pp. 6-7.

${ }^{46}$ Ibidem, p. 12.

${ }^{47}$ Ibidem, p. 16.
} 
términos de reciprocidad, conforme a los tratados que se firmasen..$^{48}$ Tuvo importantes intervenciones en materia de comercio exterior y en la elaboración del primer arancel mexicano al comercio exterior ${ }^{49}$ aprobado el 15 de diciembre de 1821 titulado Arancel general interino para gobierno de las aduanas maritimas en el comercio libre del Imperio. ${ }^{50}$

Cabe destacar que Azcárate propuso en la sesión del día 18 de octubre de 1821 lo siguiente:

"Ningún momento mejor para prohibir la esclavitud en el Imperio Mexicano, que aquel en que felizmente ha conseguido su Independencia, porque así sostiene los derechos de la naturaleza, los de la religión y los sentimientos de la razón, y el honor del Imperio y de V.M. cerrar la puerta en el todo, para ahora y siempre, mandando no se admitan esclavos en el reyno, baxo las penas que V.M. considere más proporcionadas". Esta propuesta pasó a una comisión compuesta por el propio Azcárate, Gama y Conde de Heras para su discusión.

Debemos señalar que el Colegio de Abogados se presentó ante la Junta Provisional a cumplimentar su juramento de independencia en la sesión del día 9 de octubre de $1821 . .^{51}$

Azcárate en su momento se opuso al restablecimiento de las Órdenes hospitalarias en el país. ${ }^{52}$

Fue nombrado ministro plenipotenciario ante Inglaterra por Iturbide aunque nunca fue a dicho país. En el tema de los tratados con las naciones indígenas en México Azcárate jugó un papel importante. Podemos destacar en este sentido el Tratado celebrado entre el Imperio Mexicano y la Nación Comanche el 13 de diciembre de 1822, representando al gobierno del Imperio Mexicano el Excmo. Sr. Don Francisco Azcárate y a la Nación Comanche el Capitán Guonique. ${ }^{53}$

Falleció el 31 de enero de 1831. Existe un retrato suyo al óleo en el salón de actos del Ilustre y Nacional Colegio de Abogados de México.

\footnotetext{
${ }^{48}$ Ibidem, p. 31.

${ }^{49}$ Ibidem, p. 46.

${ }^{50}$ Véase Arancel general interino para gobierno de las aduanas marítimas en el comercio libre del Imperio, en Dublán, José María Manuel y Lozano, Legislación Mexicana ó colección completa de las disposiciones legislativas expedidas desde la independencia de la República, México, Imprenta del Comercio a cargo de Dublán y Lozano, Hijos, 1876, tomo I, núm. 260.

${ }^{51}$ Diario de las sesiones de la Soberana Junta Provisional Gubernativa del Imperio Mexicano..., p. 32.

52 Ibidem, p. 105.

${ }^{53} \mathrm{Su}$ texto en Derecho Internacional Mexicano, México, Imprenta de Gonzalo A. Esteva, 1878, pp. 617619. Se reproduce también en Lecturas Jurídicas, Chihuahua, Universidad de Chihuahua, Escuela de Derecho, núm. 28, julio-septiembre, 1966, pp. 67-69.
} 


\section{Bibliografía}

“Azcárate y Lezama, D. Juan Francisco", en Diccionario Universal de historia y de geografía, Imprenta de F. Escalante, Librería de Andrade, México, 1853, t. I.

"Representación que el Ayuntamiento de México presentó al virrey José de Iturrigaray, 19 de julio de 1808", en Guedea, Virginia, Textos insurgentes (1808-1821), México, UNAM, 1998, Biblioteca del Estudiante Universitario 126.

"Representación que el Ayuntamiento de México presentó al virrey José de Iturrigaray, 5 de agosto de 1808", en Guedea, Virginia, Textos insurgentes (1808-1821), México, UNAM, 1998, Biblioteca del Estudiante Universitario 126.

Acta de la sesión del Ayuntamiento de México de 19 de julio de 1808, en Luis Navarro García, El golpe fidelista de México en 1808, Cádiz, Universidad de Cádiz, 2009.

Alamán, Lucas, Historia de Méjico, $3^{\text {a }}$ ed., Ed. Jus, Tomo Primero, 1942.

Arancel general interino para gobierno de las aduanas marítimas en el comercio libre del Imperio, en Dublán, Manuel y Lozano, José María, Legislación Mexicana ó colección completa de las disposiciones legislativas expedidas desde la independencia de la República, México, Imprenta del Comercio a cargo de Dublán y Lozano, Hijos, 1876, tomo I, núm. 260.

Ávila, Alfredo, "Nueva España, 1808-1809”, en Breña, Roberto (Editor), En el umbral de las revoluciones hispánicas: el bienio 1808-1810, México, El Colegio de México, Centro de Estudios Políticos y Constitucionales, 2010.

Breña, Roberto, El primer liberalismo español y los procesos de emancipación de América, 18081824. Una revisión historiográfica del liberalismo hispánico, México, El Colegio de México, 2006.

Cruz Barney, Oscar, "Los abogados y la independencia de México", en Koprivitza, Milena, La guerra de conciencias. Monarquía o independencia en el mundo hispánico y lusitano, Tlaxcala, Gobierno del Estado de Tlaxcala, 2010.

Derecho Internacional Mexicano, México, Imprenta de Gonzalo A. Esteva, 1878.

Diario de las sesiones de la Soberana Junta Provisional Gubernativa del Imperio Mexicano, instalada según previenen el Plan de Iguala y los Tratados de la Villa de Córdova, México, En la imprenta Imperial de D. Alexandro Valdés, 1821.

Estrada Michel, Rafael, Monarquía y Nación. Entre Cádiz y Nueva España, México, Porrúa, 2006

Herrera Peña, José, Soberanía, representación nacional e independencia en 1808, México, Senado de la República, Gobierno del Distrito Federal, 2009.

Landavazo, Marco Antonio, La máscara de Fernando VII. Discurso e imaginario monárquicos en una época de crisis. Nueva España, 1808-1822, México, El Colegio de México, Universidad Michoacana de San Nicolás de Hidalgo, El Colegio de Michoacán, 2001.

Las Siete Partidas del Sabio Rey Don Alonso el Nono, glosadas por el Licenciado Gregorio López, del Consejo Real de Indias de S.M., Madrid, En la Oficina de Benito Cano, 1789, Tomo I.

Lista de los Abogados que se hallan matriculados en el Ilustre y Real Colegio de esta Nueva España, con expresión de su antigüedad en exámen é incorporación en esta Real Audiencia como lo denotan las fechas de cada Casilla y números del margen. Sirve para este presente año de 1792, s/f, s/e.

Lista de los Abogados que se hallan matriculados en el Ilustre y Real Colegio de esta Nueva España, Con expresión de su antigüedad en exámen é incorporación en esta Real Audiencia, como lo denotan las fechas de cada casilla y números del margen, habitaciones y empleos que obtienen en el Colegio. Sirve para este presente año de 1794, En México, Por los Herederos de Don Felipe de Zúñiga y Ontiveros, Calle del Espíritu Santo, 1794.

Lista de los Abogados que se hallan matriculados en el Ilustre y Real Colegio de esta Nueva España, Con expresión de su antigüedad en exámen é incorporación en esta Real Audiencia, como lo denotan las fechas de cada casilla y números del margen, habitaciones y empleos que obtienen en el Colegio. Sirve para este presente año de 1795, En México, Por Don Mariano Joseph de Zúñiga y Ontiveros, Calle del Espíritu Santo, 1795. 
Lista de los Abogados que se hallan matriculados en el Ilustre y Real Colegio de esta Nueva España, Con expresión de su antigüedad en exámen é incorporación en esta Real Audiencia, como lo denotan las fechas de cada casilla y números del margen, habitaciones y empleos que obtienen en el Colegio. Sirve para este presente año de 1797, En México, Por Don Mariano Joseph de Zúñiga y Ontiveros, Calle del Espíritu Santo, 1797.

Lista de los Abogados que se hallan matriculados en el Ilustre y Real Colegio de esta Nueva España, Con expresión de su antigüedad en exámen é incorporación en esta Real Audiencia, como lo denotan las fechas de cada casilla y números del margen, habitaciones y empleos que obtienen en el Colegio. Sirve para este presente año de 1798, En México, Por Don Mariano Joseph de Zúñiga y Ontiveros, Calle del Espíritu Santo, 1798.

Lista de los individuos matriculados en el Ilustre y Real Colegio de Abogados de México, Con expresión del día del exámen de éstos, de su incorporación y de la de los Señores Ministros, y la de sus empleos y habitaciones, denotándose los ausentes con la letra cursiva, Sirve para el presente año de 1806, En México, Por Don Mariano Joseph de Zúñiga y Ontiveros, Calle del Espíritu Santo, 1806.

Mayagoitia, Alejandro, “Aspirantes al Ilustre y Real Colegio de Abogados de México: extractos de sus informaciones de limpieza de sangre (1760-1823)", Ars Iuris, Facultad de Derecho, Universidad Panamericana, Núm. 24, 2000.

Mayagoitia, Alejandro, “Aspirantes al Ilustre y Real Colegio de Abogados de México: extractos de sus informaciones de limpieza de sangre (1760-1823)", Ars Iuris, Facultad de Derecho, Universidad Panamericana, Núm. 21, 1999.

Mayagoitia, Alejandro, "De real a nacional: el Ilustre Colegio de Abogados de México", en La supervivencia del Derecho Español en Hispanoamérica durante la época independiente. Cuadernos del Instituto de Investigaciones Jurídicas, Instituto de Investigaciones Jurídicas, UNAM, México, 1998.

Mayagoitia, Alejandro, "Las listas de matriculados impresas por el Ilustre y Real Colegio de Abogados de México", Ars Iuris, Facultad de Derecho, Universidad Panamericana, Núm. 27, 2002.

Miquel y Vergés, José María, Diccionario de insurgentes, 2a ed., México, Porrúa, 1980.

Navarro García, Luis, El golpe fidelista de México en 1808, Cádiz, Universidad de Cádiz, 2009.

Real Decreto de 17 de noviembre de 1765, en Pérez y López, Antonio Xavier, Teatro de la Legislación Universal de España e Indias, Imprenta de Antonio Espinoza, Madrid, 1791, tomo, I.

Reflexiones sobre el cuaderno de juntas y otros que tienen relación con él, México, 28 de abril de 1809, en Navarro García, Luis, El golpe fidelista de México en 1808, Cádiz, Universidad de Cádiz, 2009.

Souto Mantecón, Matilde, Mar abierto. La política y el comercio del Consulado de Veracruz en el ocaso del sistema imperial, (México, El Colegio de México, Instituto Mora, 2001.

Valle Pavón, Guillermina del, "Participación de los mercaderes del Consulado de México en el golpe de 1808", en Collado, María del Cármen (Coord.), Miradas recurrentes II. La Ciudad de México en los siglos XIX y XX, México, Instituto Mora, Universidad Autónoma Metropolitana, 2004. 